\title{
Role of NCAN rs2228603 polymorphism in the incidence of nonalcoholic fatty liver disease: a case-control study
}

\author{
Meng-Juan Wu', Chen Yuan', Lin-Lin Lü ${ }^{2,3}$, Bai-Quan An ${ }^{1}$, Shi-Ying Xuan ${ }^{1,4^{*}}$ and Yong-Ning Xin ${ }^{14^{*}}$
}

\begin{abstract}
Background: Recently genome-wide association studies identified that NCAN rs2228603 polymorphism was associated with non-alcoholic fatty liver disease (NAFLD) mainly in subjects of European ancestry. While no research have been conducted to demonstrate the relationship between NCAN rs2228603 and NAFLD in Chinese Han adults. The aim of this study was to investigate whether NCAN rs2228603 is associated with NAFLD in Chinese population.
\end{abstract}

Methods: Gene NCAN rs2228603 was genotyped in 182 patients with NAFLD and 195 healthy controls. The expression of NCAN was tested according to polymerase chain reaction analysis (PCR) and serum lipids were performed by biology techniques.

Results: No significant difference was found in genotype and allele frequencies of NCAN rs2228603 between the NAFLD group and the controls $(P>0.05)$. Subjects with the NCAN rs2228603 CT genotype showed a higher level of alkaline phosphatase (AKP) $(P=0.017)$ and a higher high-density lipoprotein $(H D L)(P<0.05)$.

Conclusions: Our study for the first time identified that the gene NCAN rs2228603 is not a risk factor for the incidence of NAFLD in Chinese population. Also we found the dual and opposite role of T variant in protecting liver with a higher level of $\mathrm{HDL}$ and conferring risk for liver damage with a higher level of AKP.

Trial registration: Chinese Clinical Trial Register.gov Identifier: ChiCTR-ROC-15006447.

Keywords: NCAN, rs2228603, Polymorphism, Non-alcoholic fatty liver disease

\section{Background}

Non-alcoholic fatty liver disease (NAFLD), a hepatic manifestation of metabolic syndrome, is an emerging public health concern which is prevalent in individuals with metabolic derangements including obesity, insulin resistance, and diabetes mellitus $[1,2]$. As a common chronic liver disease, its spectrum ranged from simple steatosis, non-alcoholic steatohepatitis (NASH), fibrosis/cirrhosis and hepatocellular carcinoma [3, 4]. NAFLD is predicted to be the main course for liver disease world-wide by 2020 [5]. Epidemiologic studies showed a prevalence of about $20 \sim 30 \%$ in Western countries [6, 7] and 12 15\% in China depending on population and investigative methods [8],

\footnotetext{
*Correspondence: xuansydxy@163.com; xinyongning@163.com 'Department of Gastroenterology, Qingdao Municipal Hospital, Nanjing Medical University, Qingdao 266071, Shandong Province, China

Full list of author information is available at the end of the article
}

which was similar to some previous studies [9-11]. NAFLD prevalence was confirmed by variety of tools, which led to the difference. Moreover, In some areas of China where obesity is more common, which will continue to grow in a setting of increasing rates of NAFLD and other metabolic syndrome [12]. Recently, patients with NAFLD exhibited a high and rising mortality rate $[13,14]$. The most frequent causes of death are represented by liver-related diseases, cardiovascular disease and malignantneoplasms [15]. It is considered that the main course of the death in patients with NAFLD is from coronary events [16-18]. Cardiovascular disease accounted for about 25\% deaths in patients with NAFLD [19, 20]. The pathogenesis of NAFLD is still a complex disorder and multifaceted process which remains under investigation. Host genetics are considered as the significant factor for the formation and development of NAFLD [21]. 
Genome-wide association studies had assessed the correlation between NCAN and NAFLD among different ethnic groups $[14,22]$.

NCAN contains at least 20 genes in a $500 \mathrm{~kb}$ region on chromosome 19p13 and expresses neurocan, a chondroitin sulphate proteoglycan that thought to be involved in celladhesion and migration in the nervous system [23-26]. Interestingly, Nischalke's study showed $N C A N$ is not only expressed in neuronal tissue, but also in the liver [27-29]. Studies found that the SNP rs2228603 in the NCAN gene, resulting in an amino acid exchange (proline to serine) at position 92, was strongly related to the plasma low-density lipoprotein (LDL) and triglyceride (TG) levels [26]. NCAN is used to be recognized just that the central nervous system (CNS) is an important regulator of peripheral glucose and triglyceride metabolism. More studies have demonstrated that SNP rs2228603 was associated with hepatic steatosis [23, 30]. However, NCAN rs2228603 has been involved in a few studies on NAFLD among Asian. A recent study showed that SNP in NCAN was related to the higher level of ALT in Indian subjects [31]. However, Lin et al. studies showed NCAN was not a risk factor for NAFLD in obese Taiwanese children [32]. There is no research conducted between the polymorphism of NCAN and NAFLD in Chinese Han adults. The aim of this study was to investigate whether NCAN rs2228603 is associated with NAFLD in Chinese population.

\section{Methods}

\section{Subjects}

This study was performed in accordance with the principles of declaration of Helsinki and its appendices [33] and approved by the ethical committee of Qingdao municipal hospital (Qingdao, China). All patients had provided written informed consent before participation in the study.

We selected a total of 377 unrelated adult subjects from August 2012 to August 2015, including 182 patients of different genders and different ages (85 males, 97 females,) diagnosed with NAFLD and 195 healthy controls matched for genders and ages (88 males, 107 females,) who underwent B-type ultrasonography. We collected subjects from the department of gastroenterology and the medical center of Qingdao municipal hospital. All individuals were unrelated and ethnically Han Chinese adults. The diagnosis of NAFLD was made by ultrasonic imaging according to EASL and AASLD criteria. Other causes of liver disease were excluded, including increased alcohol intake (>210/140 g/ week for males/females), as confirmed by at least one family member or friend and carboxydesialylated transferrin determination, viral and autoimmune hepatitis, hereditary hemochromatosis, andalphal-antitrypsin deficiency [11]. The healthy controls were confirmed using general laboratory examinations and medical examinations at the same hospital.

\section{Biochemical parameters}

We collected venous blood samples after a 12-h overnight fast from all participants. The following data for each subject was obtained: height, body weight, waist circumference and hip circumference. Total cholesterol (TC), Triglyceride (TG), high-density lipoprotein (HDL) and low-density lipoprotein (LDL) were measured by routine enzymatic methods. Serum concentrations of gamma-glutamyltranspeptidase (GGT), Total bilirubin (TBIL), alkaline phosphatase (AKP), glucose (GLU), Uric acid (UA), alanine aminotransferase (ALT) and aspartate aminotransferase (AST) were tested with available standardized methods. Environmental factors were excluded in the study.

\section{Genotyping}

Genomic DNA was isolated from peripheral blood using purification kit (BioTeke, Biotechnology, Beijing, China) according to the manufacturer's instructions. After extraction, the genomic DNA was stored at $-20{ }^{\circ} \mathrm{C}$ before use. Genotyping for NCAN (rs2228603) was performed by polymerase chain reaction (PCR) using the following primers for NCAN polymorphism: 5'-TGGCATCGTGATGGACTCC-3', 5' -AATGTCACGCACGATTTCC C-3'. PCR amplification was performed under the following conditions: $10 \mathrm{~min}$ at $95{ }^{\circ} \mathrm{C}$, then 50 cycles before denaturation at $94{ }^{\circ} \mathrm{C}$ for $1 \mathrm{~min}$, annealing at $60{ }^{\circ} \mathrm{C}$ for $1 \mathrm{~min}$ and elongation $1 \mathrm{~min}$ at $70{ }^{\circ} \mathrm{C}$. Direct DNA sequencing, the $\mathrm{ABI}$ Prism sequence detection system ABI3730 (Foster city, CA, USA), was taken for the assay of NCAN genotypes. The average genotype call rate was $>95 \%$ and the genotype concordance rate of blind replicates was $>99 \%$.

\section{Statistical analysis}

Statistical analysis was carried out using SPSS Statistics software version 17.0 (SPSS Inc. Chicago, IL, USA). Genotype and alleles were obtained using chi-square test and the $\chi^{2}$ test was applied to assess DNA distributions between NAFLD patients and the controls. The baseline characteristics of participants were presented as mean \pm standard deviation. The differences in characteristics between different groups were tested by the Student's $t$ test, paired samples $t$ test or $\chi 2$ test. Logistic regression analysis was performed to estimate the association of polymorphism with NAFLD. A $P$ value $<0.05$ was considered statistically significant. 


\section{Results}

\section{Clinical characteristics of the participants}

We investigated 182 NAFLD patients and 195 controls matched for age $(P=0.000)$ and gender $(P=0.759)$. Table 1 showed the clinical characteristics and serum lipid levels of the subjects. Compared to the controls, NAFLD patients showed increased age, weight, Waist circumference, Hip circumference, serum ALT, AST, GGT, AKP, GLU, UA, TG, TC and LDL, however the level of HDL decreased. These results had significant differences.

\section{NCAN rs2228603 genotypes and allele distribution}

The genotypes distribution of the NCAN rs2228603 corresponded to the Hardy-Weinberg equilibriumin in NAFLD and control groups $\left(\mathrm{P}_{\mathrm{NAFLD}}=0.179 ; \mathrm{P}_{\text {control }}\right.$ $=0.101$, respectively). To ensure the accuracy of genotyping, DNA sequencing was repeated in 150 subjects for reverse sequencing. Distribution of NCAN genotypes was shown in Table 2, which demonstrated that there were no significant differences between the patients with NAFLD and the healthy controls $(P>0.05)$. The gene NCAN rs2228603 was not a risk factor in the prevalence and pathogenesis of NAFLD $(\mathrm{OR}=0.832,95 \% \mathrm{CI}$ : 0.499-1.386).

\section{Genetic association of NCAN rs2228603 with NAFLD}

To evaluate whether the selected SNP influence the laboratory parameters, all variants in carriers and non-
Table 2 Correlation of the polymorphism in gene NCAN with risk of NAFLDa

\begin{tabular}{lllll}
\hline NCAN (Rs2228603) & NAFLD patients $(n)$ & Controls $(n)$ & $X^{2}$ & $P$ value \\
\hline Genotypes & & & 0.500 & 0.480 \\
CT & 33 & 41 & & \\
CC & 149 & 154 & & \\
$T T$ & 0 & 0 & 0.445 & 0.505 \\
Allele C & & & & \\
T & 33 & 41 & & \\
C & 331 & 349 & & \\
\hline
\end{tabular}

Abbreviation: NAFLD non-alcoholic fatty liver disease patients ${ }^{a} p$ : NAFLD patients vs. Control

carriers were examined. As shown in Table 3, there was strongly difference in AKP $(P=0.017)$ between subjects with allele $\mathrm{T}$ and subjects without allele $\mathrm{T}$ in overall series. Meanwhile, a significant difference of HDL $(P<$ $0.05)$ was observed in all subjects and healthy controls. However, other serological markers did not reach the statistical difference $(P>0.05)$.

\section{Discussion}

Recently the gene NCAN on NAFLD has been studied, however, the results were controversial [23, 34]. The present study firstly evaluated the association between rs2228603 polymorphism in the gene NCAN and NAFLD in Chinese population. Our study selected 182 NAFLD patients and 195 healthy controls to observe the

Table 1 Demographics and clinical characteristics of Patients with NAFLD and Controls ${ }^{\mathrm{a}}$

\begin{tabular}{llll}
\hline Characteristics & NAFLD patients $(n=182)$ & Controls $(n=195)$ & $p$ Value \\
\hline Age, $y$ & $46.09 \pm 11.59$ & $40.64 \pm 11.53$ & 0.000 \\
Gender, Female/Male & $97 / 85$ & $107 / 88$ & 0.759 \\
Height, cm & $167.17 \pm 10.55$ & $166.09 \pm 6.46$ & 0.237 \\
Weight, kg & $74.28 \pm 11.44$ & $63.38 \pm 11.10$ & 0.000 \\
Waist circumference, cm & $92.29 \pm 9.29$ & $82.46 \pm 8.85$ & 0.000 \\
Hip circumference, cm & $103.11 \pm 8.21$ & $96.87 \pm 8.80$ & 0.000 \\
ALT, U/L & $25.63 \pm 14.41$ & $19.71 \pm 10.49$ & 0.000 \\
AST, U/L & $21.90 \pm 11.23$ & $19.64 \pm 6.46$ & 0.018 \\
GGT, U/L & $22.19 \pm 9.62$ & $14.88 \pm 5.69$ & 0.000 \\
TBIL, umol/L & $13.95 \pm 6.40$ & $13.36 \pm 5.30$ & 0.329 \\
AKP, U/L & $68.18 \pm 18.35$ & $59.79 \pm 13.81$ & 0.000 \\
GLU, mmol/L & $5.57 \pm 1.79$ & $4.96 \pm 1.20$ & 0.000 \\
UA, umol/L & $364.42 \pm 187.65$ & $301.10 \pm 76.82$ & 0.000 \\
TG, mmol/L & $1.98 \pm 1.78$ & $1.27 \pm 1.58$ & 0.000 \\
TC, mmol/L & $4.92 \pm 0.95$ & $4.64 \pm 0.93$ & 0.004 \\
HDL, mmol/L & $1.29 \pm 0.46$ & $1.48 \pm 0.33$ & 0.000 \\
LDL, mmol/L & $3.30 \pm 0.93$ & $2.94 \pm 0.80$ & 0.000 \\
\hline Abbrevilin & &
\end{tabular}

Abbreviation: ALT Alanine aminotransferase, AST Aspartate aminotransferase, GGT gamma-glutamyltranspeptidase, TBIL Total bilirubin, AKP alkaline phosphatase, GLU glucose, UA Uric acid, TG Triglyceride, TC Total cholesterol, HDL high-density lipoprotein, LDL low-density lipoprotein

${ }^{\mathrm{a}}$ Data are presented as Mean \pm SD 
Table 3 Analysis of clinical characteristics in NCAN (rs2228603 C/T) carriers and non-carriers of the study population ${ }^{\mathrm{a}}$

\begin{tabular}{|c|c|c|c|c|c|c|c|c|c|}
\hline \multirow[t]{2}{*}{ Characteristic } & \multicolumn{3}{|l|}{ Overall series } & \multicolumn{3}{|l|}{ NAFLD patients } & \multicolumn{3}{|l|}{ Controls } \\
\hline & Carriers & Non-carriers & P & Carriers & Non-carriers & P & Carriers & Non-carriers & $P$ \\
\hline Age, y & $44.74 \pm 11.20$ & $42.91 \pm 12.01$ & 0.234 & $48.58 \pm 10.69$ & $45.54 \pm 11.74$ & 0.174 & $41.66 \pm 10.74$ & $40.36 \pm 11.75$ & 0.524 \\
\hline Female/male & $45 / 29$ & $200 / 103$ & 0.401 & $14 / 19$ & $83 / 66$ & 0.166 & $31 / 10$ & $117 / 37$ & 0.961 \\
\hline Height, cm & $167.35 \pm 7.76$ & $166.43 \pm 8.89$ & 0.416 & $168.45 \pm 8.20$ & $166.89 \pm 11.00$ & 0.441 & $166.46 \pm 7.36$ & $166.00 \pm 6.22$ & 0.682 \\
\hline Weight, Kg & $68.41 \pm 11.77$ & $68.70 \pm 12.67$ & 0.857 & $71.39 \pm 10.34$ & $74.91 \pm 11.61$ & 0.110 & $66.00 \pm 12.41$ & $62.69 \pm 10.60$ & 0.123 \\
\hline$A L T, U / L$ & $22.43 \pm 12.41$ & $22.60 \pm 12.99$ & 0.920 & $24.55 \pm 12.09$ & $25.87 \pm 14.90$ & 0.633 & $20.73 \pm 12.55$ & $19.44 \pm 9.90$ & 0.483 \\
\hline AST, U/L & $20.68 \pm 8.04$ & $20.75 \pm 9.40$ & 0.953 & $20.45 \pm 5.84$ & $22.22 \pm 12.09$ & 0.415 & $20.85 \pm 9.52$ & $19.32 \pm 5.36$ & 0.177 \\
\hline GGT, U/L & $17.77 \pm 7.631$ & $18.56 \pm 8.872$ & 0.479 & $20.67 \pm 8.855$ & $22.52 \pm 9.776$ & 0.317 & $15.44 \pm 5.572$ & $14.73 \pm 5.735$ & 0.482 \\
\hline TBIL, umol/L & $13.43 \pm 5.41$ & $13.70 \pm 5.97$ & 0.725 & $12.28 \pm 4.94$ & $14.32 \pm 6.64$ & 0.097 & $14.36 \pm 5.64$ & $13.09 \pm 5.19$ & 0.174 \\
\hline AKP, U/L & $65.18 \pm 13.75$ & $64.73 \pm 17.22$ & 0.017 & $69.94 \pm 16.51$ & $69.34 \pm 18.60$ & 0.070 & $67.95 \pm 10.75$ & $60.28 \pm 14.50$ & 0.258 \\
\hline Glu. mmol/L & $5.04 \pm 0.86$ & $5.31 \pm 1.66$ & 0.182 & $5.21 \pm 1.09$ & $5.66 \pm 1.90$ & 0.194 & $4.91 \pm 0.60$ & $4.98 \pm 1.32$ & 0.756 \\
\hline UA, umol/L & $307.59 \pm 81.35$ & $337.55 \pm 156.11$ & 0.111 & $335.42 \pm 98.44$ & $370.85 \pm 201.84$ & 0.328 & $285.20 \pm 56.33$ & $305.33 \pm 81.03$ & 0.136 \\
\hline $\mathrm{TG}, \mathrm{mmol} / \mathrm{L}$ & $1.46 \pm 1.28$ & $1.65 \pm 1.81$ & 0.381 & $2.00 \pm 1.67$ & $1.98 \pm 1.81$ & 0.964 & $1.03 \pm 0.57$ & $1.34 \pm 1.75$ & 0.263 \\
\hline $\mathrm{TC}, \mathrm{mmol} / \mathrm{L}$ & $4.80 \pm 0.92$ & $4.77 \pm 0.96$ & 0.825 & $4.88 \pm 0.83$ & $4.93 \pm 0.98$ & 0.799 & $4.73 \pm 0.98$ & $4.62 \pm 0.92$ & 0.493 \\
\hline $\mathrm{HDL}, \mathrm{mmol} / \mathrm{L}$ & $1.47 \pm 0.25$ & $1.37 \pm 0.44$ & 0.009 & $1.31 \pm 0.26$ & $1.29 \pm 0.50$ & 0.861 & $1.60 \pm 0.14$ & $1.44 \pm 0.36$ & 0.000 \\
\hline $\mathrm{LDL}, \mathrm{mmol} / \mathrm{L}$ & $3.04 \pm 0.85$ & $3.13 \pm 0.89$ & 0.452 & $3.18 \pm 0.68$ & $3.33 \pm 0.98$ & 0.403 & $2.94 \pm 0.96$ & $2.94 \pm 0.76$ & 0.985 \\
\hline
\end{tabular}

Abbreviations: ALT Alanine aminotransferase, AST Aspartate aminotransferase, GGT gamma-glutamyltranspeptidase, TBIL Total bilirubin, AKP alkaline phosphatase, GLU glucose, UA Uric acid, TG Triglyceride, TC Total cholesterol, HDL high-density lipoprotein, LDL low-density lipoprotein

${ }^{\mathrm{a}}$ Data are presented as Mean \pm SD

correlation between NCAN rs2228603 and NAFLD. We found no carriers with TT genotype both in NAFLD and control group, also no significant association of NCAN rs2228603 with NAFLD was observed in our subjects, which latter was consistent with some previous findings [32, 34, 35]. While Speliotes et al. identified that variant in the gene NCAN was strongly associated with histologic NAFLD and increasing computed tomography (CT) hepatic steatosis [14]. Rs2228603 is located in exon 3 of NCAN and encodes anon-conservative nonsynonymous mutation (Pro92Ser), which is predicted by the software tool PolyPhen-2 to alter protein structure and function [36]. It is plausible that this variant increases the risk for NAFLD through influencing dietary fat intake by modulated by a brain-liver axis [26, 37]. We characterized the effect of allele $\mathrm{T}$ variant in our groups, which expand further evidence for central control of liver lipid metabolism.

We found, for the first time, an obvious difference between variant carriers and non-carriers regarding AKP. The results showed that NCAN rs2228603 CT genotype had a higher level of AKP in overall subjects. AKP is a hydrolase enzyme that commonly used as signal amplification in bone metabolism. Matthew's study showed that isolated elevated AKP and risk factors for NAFLD should be evaluated for evidence of significant steatohepatitis [38]. However, the mechanism of AKP in the pathogenesis of NAFLD remains unclear and warrants further exploration. The result may provide evidence that carriage of $\mathrm{T}$ allele can elevate AKP to strengthen liver damage.
Meanwhile, we found a protected role of the variant in lipid metabolism, and observed that the $\mathrm{T}$ allele carriers had a higher serum HDL level than the $\mathrm{T}$ allele noncarriers, whereas no significant correlation was observed in LDL-cholesterol, total cholesterol and triglyceride levels with variant carriers. Gorden et al. study found $\mathrm{T}$ allele carriers showed a lower serum LDL-cholesterol, total cholesterol and triglyceride levels, particularly in those with NAFLD [23]. Approximately 20 80\% NAFLD patients have dyslipidemia [39]. HDL is negatively related to the incidence of atherosclerosis and a decreased level of HDL might indicate the clinical damage to liver cells, while we could not deny the possible influence of the elevated HDL-cholesterol on the association between $N C A N$ and NAFLD among different population. A recent study showed that NCAN is expressed at the luminal side of cholangiocytes and in vesicles of hepatocytes, which may imply that besides its role in the nervous system, NCAN may be involved in transport processes of the liver [27]. Elevated serum HDLcholesterol has certain protective effect to the liver; however, the mechanism is still unclear and further studies are needed to validate this argument.

\section{Conclusion}

In conclusion, this study elucidated that there was no association between NCAN rs2228603 polymorphism and incidence of NAFLD in Chinese population for the first time. The NCAN rs2228603 T-allele significantly affects serum AKP and HDL. We can assume that NCAN 
rs2228603 is mainly involved in the progress of NASH by influence liver damage based on simple steatosis. The variant may be a protective factor in early stage. Further studies with large scale of subjects and different ethnicity are needed to estimate the impact of NCAN rs2228603 on NAFLD. Hopefully, additional research on the role of NCAN in NAFLD might help to elevate the application of future therapeutic strategies and interventions.

\section{Acknowledgements}

We thank Nanjing Medical University, Qingdao Municipal Hospital and all the participants in the present study for cooperation in data collection.

\section{Funding}

This research was supported by Qingdao livelihood, science and technology project, China (grant No.14-2-3-17-nsh) and Qingdao key health discipline development fund.

\section{Availability of data and materials}

We do not wish to share our data and materials.

\section{Authors' contributions}

Study concept and design: SYX, YNX. Acquisition and analysis of data: MJW CY. LLL, BQA. The drafting of the manuscript: MJW, CY. Approval of the final manuscript: MJW, CY, LLL, BQA, SYX, YNX.

\section{Competing interests}

The authors declare that they have no competing interests.

\section{Consent for publication}

Not applicable.

\section{Ethics approval and consent to participate}

This study was performed in accordance with the principles of declaration of Helsinki and its appendices [33] and approved by the ethical committee of Qingdao municipal hospital (Qingdao, China). All patients had provided written informed consent before participation in the study.

\section{Author details}

${ }^{1}$ Department of Gastroenterology, Qingdao Municipal Hospital, Nanjing Medical University, Qingdao 266071, Shandong Province, China. ${ }^{2}$ Digestive Disease Key Laboratory of Qingdao, Qingdao, Shandong Province, China. ${ }^{3}$ Central Laboratories, Qingdao Municipal Hospital, Qingdao, Shandong Province, China. ${ }^{4}$ Department of Gastroenterology, Qingdao Municipal Hospital, Qingdao, Shandong Province, China.

Received: 13 August 2016 Accepted: 9 November 2016

Published online: 26 November 2016

\section{References}

1. Kim BJ, Cheong ES, Kang JG, Kim BS, Kang JH. Relationship of epicardial fat thickness and nonalcoholic fatty liver disease to coronary artery calcification: from the CAESAR study. J Clin Lipidol. 2016;10:619-26. e611.

2. Lonardo A, Ballestri S, Marchesini G, Angulo P, Loria P. Nonalcoholic fatty liver disease: a precursor of the metabolic syndrome. Dig Liver Dis. 2015;47:181-90.

3. Alam S, Mustafa G, Alam M, Ahmad N. Insulin resistance in development and progression of nonalcoholic fatty liver disease. World J Gastrointest Pathophysiol. 2016;7:211-7.

4. Younossi ZM, Stepanova M, Rafiq N, Makhlouf H, Younoszai Z, Agrawal R, Goodman Z. Pathologic criteria for nonalcoholic steatohepatitis: interprotocol agreement and ability to predict liver-related mortality. Hepatology. 2011;53:1874-82

5. Leon-Mimila P, Vega-Badillo J, Gutierrez-Vidal R, Villamil-Ramirez H, VillarealMolina T, Larrieta-Carrasco E, Lopez-Contreras BE, Kauffer LR, MaldonadoPintado DG, Mendez-Sanchez N, et al. A genetic risk score is associated with hepatic triglyceride content and non-alcoholic steatohepatitis in Mexicans with morbid obesity. Exp Mol Pathol. 2015;98:178-83.
6. Shang XR, Song JY, Liu FH, Ma J, Wang HJ. GWAS-identified common variants with nonalcoholic fatty liver disease in Chinese children. J Pediatr Gastroenterol Nutr. 2015;60:669-74

7. Milic S, Stimac D. Nonalcoholic fatty liver disease/steatohepatitis: epidemiology, pathogenesis, clinical presentation and treatment. Dig Dis. 2012:30:158-62

8. Sayiner M, Koenig A, Henry L, Younossi ZM. Epidemiology of nonalcoholic fatty liver disease and nonalcoholic steatohepatitis in the United States and the rest of the world. Clin Liver Dis. 2016;20: 205-14.

9. Kamei J, Nozaki C, Saitoh A. Effect of mexiletine on vincristine-induced painful neuropathy in mice. Eur J Pharmacol. 2006;536:123-7.

10. Zhou YJ, Li YY, Nie YQ, Huang CM, Cao CY. Natural course of nonalcoholic fatty liver disease in southern China: a prospective cohort study. J Dig Dis. 2012;13:153-60.

11. Niu TH, Jiang $M$, Xin YN, Jiang XJ, Lin ZH, Xuan SY. Lack of association between apolipoprotein C3 gene polymorphisms and risk of nonalcoholic fatty liver disease in a Chinese Han population. World J Gastroenterol. 2014; 20:3655-62.

12. Fan JG, Farrell GC. Epidemiology of non-alcoholic fatty liver disease in China. J Hepatol. 2009:50:204-10.

13. Harrison SA, Neuschwander-Tetri BA. Nonalcoholic fatty liver disease and nonalcoholic steatohepatitis. Clin Liver Dis. 2004;8:861-79. ix.

14. Speliotes EK, Yerges-Armstrong LM, Wu J, Hernaez R, Kim LJ, Palmer CD, Gudnason V, Eiriksdottir G, Garcia ME, Launer LJ, et al. Genome-wide association analysis identifies variants associated with nonalcoholic fatty liver disease that have distinct effects on metabolic traits. PLoS Genet. 2011; 7:e1001324

15. Tarquini R, Lazzeri C, Boddi M, Marra F, Abbate R, Gensini GF. [Non-alcoholic fatty liver disease: a new challenge for cardiologists]. G Ital Cardiol (Rome). 2010;11:660-9.

16. Ercin CN, Dogru T, Celebi G, Gurel H, Genc H, Sertoglu E, Bagci S. The relationship between blood urea nitrogen levels and metabolic, biochemical, and histopathologic findings of nondiabetic, nonhypertensive patients with nonalcoholic fatty liver disease. Turk J Med Sci. 2016:46:985-91.

17. Treeprasertsuk S, Lopez-Jimenez F, Lindor KD. Nonalcoholic fatty liver disease and the coronary artery disease. Dig Dis Sci. 2011:56:35-45.

18. Lizardi-Cervera J, Aguilar-Zapata D. Nonalcoholic fatty liver disease and its association with cardiovascular disease. Ann Hepatol. 2009:8 Suppl 1:S40-3.

19. Adams LA, Lymp JF, St Sauver J, Sanderson SO, Lindor KD, Feldstein A, Angulo $P$. The natural history of nonalcoholic fatty liver disease: a population-based cohort study. Gastroenterology. 2005;129:113-21.

20. Du SX, Lu LL, Liu Y, Dong QJ, Xuan SY, Xin YN. Association of adiponectin gene polymorphisms with the risk of coronary artery disease in patients with nonalcoholic fatty liver disease in a Chinese Han population. Hepat Mon. 2016:16:e37388.

21. Stickel F, Hampe J. Genetic determinants of alcoholic liver disease. Gut. 2012;61:150-9.

22. Petersen KF, Dufour S, Hariri A, Nelson-Williams C, Foo JN, Zhang XM, Dziura J, Lifton RP, Shulman Gl. Apolipoprotein C3 gene variants in nonalcoholic fatty liver disease. N Engl J Med. 2010;362:1082-9.

23. Gorden A, Yang R, Yerges-Armstrong LM, Ryan KA, Speliotes $E$, Borecki IB, Harris TB, Chu X, Wood GC, Still CD, et al. Genetic variation at NCAN locus is associated with inflammation and fibrosis in non-alcoholic fatty liver disease in morbid obesity. Hum Hered. 2013;75:34-43

24. Nault JC, Nahon P. Genetic predisposition to hepatocellular carcinoma in alcoholic cirrhosis: the NCAN-PNPLA3-lipid connection? J Hepatol. 2014;61:971-2.

25. Zhou L, Ding H, Zhang X, He M, Huang S, Xu Y, Shi Y, Cui G, Cheng L, Wang $\mathrm{QK}$, et al. Genetic variants at newly identified lipid loci are associated with coronary heart disease in a Chinese Han population. PLoS One. 2011;6:e27481.

26. Willer CJ, Sanna S, Jackson AU, Scuteri A, Bonnycastle LL, Clarke R, Heath SC, Timpson NJ, Najjar SS, Stringham HM, et al. Newly identified loci that influence lipid concentrations and risk of coronary artery disease. Nat Genet. 2008;40:161-9.

27. Nischalke HD, Lutz P, Kramer B, Sohne J, Muller T, Rosendahl J, Fischer J, Berg T, Hittatiya K, Fischer HP, et al. A common polymorphism in the NCAN gene is associated with hepatocellular carcinoma in alcoholic liver disease. J Hepatol. 2014;61:1073-9. 
28. Lam TK, Gutierrez-Juarez R, Pocai A, Bhanot S, Tso P, Schwartz GJ, Rossetti L. Brain glucose metabolism controls the hepatic secretion of triglyceride-rich lipoproteins. Nat Med. 2007;13:171-80.

29. Nogueiras R, Wiedmer P, Perez-Tilve D, Veyrat-Durebex C, Keogh JM, Sutton GM, Pfluger PT, Castaneda TR, Neschen S, Hofmann SM, et al. The central melanocortin system directly controls peripheral lipid metabolism. J Clin Invest. 2007;117:3475-88.

30. Hernaez R, McLean J, Lazo M, Brancati FL, Hirschhorn JN, Borecki IB, Harris TB, Genetics of Obesity-Related Liver Disease C, Nguyen T, Kamel IR, et al. Association between variants in or near PNPLA3, GCKR, and PPP1R3B with ultrasound-defined steatosis based on data from the third National Health and Nutrition Examination Survey. Clin Gastroenterol Hepatol. 2013;11:118390. e1182.

31. Kanth W, Sasikala M, Rao PN, Steffie Avanthi U, Rao KR, Nageshwar Reddy D. Pooled genetic analysis in ultrasound measured non-alcoholic fatty liver disease in Indian subjects: a pilot study. World J Hepatol. 2014;6:435-42.

32. Lin YC, Chang PF, Chang MH, Ni YH. Genetic variants in GCKR and PNPLA3 confer susceptibility to nonalcoholic fatty liver disease in obese individuals. Am J Clin Nutr. 2014;99:869-74.

33. Rickham PP. Human experimentation. Code of ethics of the World Medical Association. Declaration of Helsinki. Br Med J. 1964;2:177.

34. Kitamoto A, Kitamoto T, Nakamura T, Ogawa Y, Yoneda M, Hyogo H, Ochi H, Mizusawa S, Ueno T, Nakao K, et al. Association of polymorphisms in GCKR and TRIB1 with nonalcoholic fatty liver disease and metabolic syndrome traits. Endocr J. 2014;61:683-9.

35. Kawaguchi T, Sumida Y, Umemura A, Matsuo K, Takahashi M, Takamura T, Yasui K, Saibara T, Hashimoto E, Kawanaka M, et al. Genetic polymorphisms of the human PNPLA3 gene are strongly associated with severity of nonalcoholic fatty liver disease in Japanese. PLoS One. 2012;7:e38322.

36. Adzhubei IA, Schmidt S, Peshkin L, Ramensky VE, Gerasimova A, Bork P, Kondrashov AS, Sunyaev SR. A method and server for predicting damaging missense mutations. Nat Methods. 2010;7:248-9.

37. Cohn JS, Wagner DA, Cohn SD, Millar JS, Schaefer EJ. Measurement of very low density and low density lipoprotein apolipoprotein (Apo) B-100 and high density lipoprotein Apo A-I production in human subjects using deuterated leucine. Effect of fasting and feeding. J Clin Invest. 1990;85:804-11.

38. Pantsari MW, Harrison SA. Nonalcoholic fatty liver disease presenting with an isolated elevated alkaline phosphatase. J Clin Gastroenterol. 2006;40:633-5.

39. Souza MR, Diniz Mde F, Medeiros-Filho JE, Araujo MS. Metabolic syndrome and risk factors for non-alcoholic fatty liver disease. Arq Gastroenterol. 2012; 49:89-96.

\section{Submit your next manuscript to BioMed Central and we will help you at every step:}

- We accept pre-submission inquiries

- Our selector tool helps you to find the most relevant journal

- We provide round the clock customer support

- Convenient online submission

- Thorough peer review

- Inclusion in PubMed and all major indexing services

- Maximum visibility for your research

Submit your manuscript at www.biomedcentral.com/submit

) Biomed Central 